\title{
Study on the Theory and Practical Innovation New Path of Public Physical Education Curriculum Reform in Chinese Universities "under the Vision Field of Health China"
}

\author{
Yingshu $\mathrm{Hu}^{1}$ and Xiangqi Tang ${ }^{2}$
}

\author{
${ }^{1}$ School of Physical Education, Southwest Petroleum University, Chengdu 6100, Sichuan Province \\ China; ${ }^{2}$ Southwest Petroleum University, Chengdu, Sichuan Province, China
}

\begin{abstract}
Public physical education curriculum is an important part of the curriculum system of colleges and universities in China. It is the core content of sports work deployment. It is also an important way to build sports culture on campus and it is also necessary to carry out quality-oriented education and cultivate college students' physical and mental health. However, with the social progress, the rapid development of educational undertakings, increasingly different personality and ever-changing fitness methods of students, college public physical education has been unable to fully adapt to the development of the times and the needs of personnel training. This paper discusses and analyzes the current situation of skills training of physical education curriculum, physical education curriculum provision, concept of physical education body building, planning of physical curriculum extracurricular and intracurricular activities, construction of physical education campus culture activities and construction of physical education curriculum teaching staff of the public physical curriculum in several colleges and universities and the several factors of the existing abuse of Chinese public physical curriculum. This paper further explores the development and innovation of the reform of public physical education curriculum in our country from the view field of "health China", and provides theoretical reference for the reform of public physical education in colleges and universities, as well as lays a solid foundation for promoting college students' "lifelong sports concept".
\end{abstract}

Keywords: Health China; College public physical education curriculum; Reform theory; Practice innovation; Lifelong sports

\section{“健康中国视域下”我国高校公共体育课程改革 理论与实践创新路径研究}

胡英姝 ${ }^{1}$, 唐湘琪

(1.西南石油大学体育学院, 四川省成都市, 邮编 610000; 2.西南石油大学, 四川省成都市, 邮编 610000 )

摘要：公共体育课程是我国高校课程体系中的重要组成部分, 是体育工作部署的核心内容, 是校园体育文化建设的重 要途径, 也是高校实施素质教育和培养大学生身心健康全面发展的必要环节。然而, 随着社会的进步, 教育事业的快速发展、 大学生个性日益鲜明的差异化和日新月异的健身方式, 高校公共体育课已经不能完全的适应时代的发展和人才培养的需求。 通过对我国多所高校公共体育课程的体育教学技能培养、体育课程设置、体育强身观念、体育课内外活动策划、体育校园文 化活动组织、体育师资队伍建设等发展现状和我国公共体育课程现存的弊端问题进行若干因素的探讨与分析, 从 “健康中国 视域下” 对我国高校公共体育课程改革思路的发展与创新进行进一步探索, 为高校公共体育课从改革提供理论参考依据, 为 促进大学生“终身体育观” 打下扎实基础。

关键词: 健康中国；高校公共体育课程；改革理论；实践创新；终身体育

引言

自 2012 年党的十八大会议成功召开以来, 党中央就把 “健康中国” 提升为国家战略, 伴随着《十三 五规划纲要》、《“健康中国 2020” 战略研究报告》等相关文件的颁布, 深刻表明全民健康体质已经不仅关 
乎学校体育教育培养, 更是国家层面关心的重大民生问题。作为学校体育教育的最后阶段, 高校无疑也将 面临着 21 世纪人才培养的革新与挑战, 大学生在高校体育教育的学习程度、体育技能的掌握、体育健身 意识的培养、体育锻炼的习惯都将影响着他们日后的学习、工作、甚至一生。然而, 根据教育部近年来对 我国普通高等院校大学生体测数据监测发现, 我国大学生的实际健康状况却不容乐观, 这不发引人深思是 我国体育教育改革上出现了问题, 还是大学生们身体健康状况日愈下降, 应对此现象, 体育教育改革势在 必行。传统的体育教育理念上, 始终把 “学校教育树立健康第一为指导思想”, 把强身健体、增强体质作 为体育教学的核心, 然而却忽略了教育的真正涵义, 作为 21 世纪新型复合人才的大学生们, 体育教育理 念也应该与时转变, “强身健体是体育教育的终极目标, 终身体育健身观念是教育的核心”, 高校公共体育 课程在教育的同时也要培养大学生们的体健身意识, 树立 “终身体育观”, 养成良好的健身习惯, 从行动 上引以指导, 从思想上引以改变, 同时, 作为高校有责任和有义务, 根据学校办学情况和特色, 勇于深化 体育教育改革和增强体制创新, 积极丰富校园体育文化活动, 营造良好的健身氛围, 促进大学生们加强对 公共体育课程的喜爱, 为大学生们身心全面健康发展提供有力的保障。

\section{1 我国高校公共体育课程教育发展演变过程与现状分析}

建国六十多年以来, 我国高校体育教育改革之路百曲千折, 历经风雨发生了许多历史性的变化, 取得 了很多显赫的成就, 经历了体育教育改革的: “模仿学习阶段、建设起步阶段、改革探索阶段、提高发展 阶段”。而在此期间, 我国也陆续从 1956 年、1961 年、1979 年、1992 年分别颁布了《一般高等学习体育 课实行教学大纲》、《高等学习普通体育课教材纲要》、《高等学习普通体育课教学大纲》、《全国普通高等学 习体育课程教学指导纲要》等文件来指导和促进我国体育教育的改革和发展。然而, 科技信息时代的变化, 让高校在培养学生文化教育的同时却忽略了体育教育的真正意义, 使体育教育任然长期处于学校教学体系 的边缘地位, 随着国家对于大学生体质的重视以及出台多部文件之后, 高校体育才被逐渐得以 “重视”。 无论高校, 还是学校体育教育的不同阶段, 体育课程还处于一种理性下的被动参与, 这违背了体育教育的 本质涵义。而我国现今高校对于大学生体育教育培养的问题则主要出现在以下方面:

（1）弱化了体育教育 “育人” 的基础，形式化的视体育为一门必修的课程。

(2) 体育课程任务形式化, 忽略教学的主要内容和教育目标。

(3) 注重大学生兴趣为导向的同时忽略了统体育教学的科学性与系统性。

（4）减弱了体育多元化功能, 形成以大学生体质增强和体育教育精神的培养的不均衡。

（5）忽略大学生 “终身体育观” 的培养, 疏忽校园体育文化的建设。

体育教育发展至今, 已经形成了特有的教育规律和教学体系。而瑞士著名的教育实践家和理论家约翰 -亨利希・裴斯泰洛齐则认为: “通过身体练习获得优于本能的意志品质” 才算是真正的体育教育。他强调: “体育教学不应该是单纯对人体行为锻炼的建构过程, 更应该是人的精神成长的构建过程”。因此, 现今 我国高校公共体育课程就在此方面的教育引发了很多问题。公共体育课是作为高校实施体育教育的载体, 是大学生们在高校培养身心健康全面发展、体育知识技能、体育锻炼行为、终身体育观念等方面的最有效 途径, 公共体育课程实施效果将直接影响着大学生们对体育锻炼和体育意识行为的价值取向。

\section{2 “健康中国视域下” 我国高校公共体育课程转型与发展导向}

“健康中国 2020” 战略的提出, 深刻表明我国已经把全民健康问题上升为国家战略计划, 不仅是对我 
国全民健康的促进，也是对我国高校大学生身心全面健康发展的有力保障。而作为高校应该提高警惕，与 时俱进, 紧跟时代步伐, 在健康中国视域下, 在对于培养新型复合性人才的大学生上的公共体育课程有应 该做出积极的转型，使大学生通过体育锻炼，改善民族体质，通过体育教育，培养“尚武精神”。

习近平总书记多次在会议上强调：“没有全民健康，就没有全面小康，健康是促进人的全面发展的必 然要求, 是经济社会发展的基础条件, 是民族昌盛和国家富强的重要标志”。而体育在我国高校的角色, 就承担了巨大的健康促进责任。体育它不仅仅是一种身体肢体和肌肉的运动, 更是一种现代化素质教育手 段, 一种情感寄托, 一种健康生活方式, 一种精神文明的载体, 而公共体育课程的转型将直接影响着大学 生们对于体育教育的认识和体育发展导向。自 2014 年, 国家颁布了《国家学生体质健康标准 (2014 年修订)》 文件后, “引体向上” 就成全了我国大学生体质测试的最大弱项, 上肢力量的薄弱和身体综合素质的不堪 都都我国公共体育课程应该去努力和改进的方向, 公共体育课程在培养技能掌握的同时也要注重学生综合 运动能力的提升, 寻求大学生身心健康和运动素质能力均衡发展。

\section{3 我国高校公共体育课程改革理论探究}

根据近年来我国高校大学生体质健康监测数据来看, 大学生健康体质呈现出日骤下滑趋势，而如何提 高与改善大学生体质, 这是高校体育教学改革中面临的首要任务。面对日益严峻的社会形势和大学生文化 学习的功课压力, 当下之急对于高校公共体育课程改革理论的关键环节就一定要建立在改变体育教育教学 方式的转变, 教学方法的增强, 注重培养大学生 “软实力” 行为意识的构建。而高校公共体育课程改革理 论思路则表现在以下方面:

\section{1 “以人为本, 健康第一, 体教育人”}

进入 21 世纪以来, 基于 “以人为本” 的教学理念下, “健康第一” 的核心价值观成功被提炼出来, 并 成为我国各大高校公共体育课程改革的动力, 它不仅符合大学生全面健康发展的观念, 也符合国我国全民 体质健康建设的理念。然而, 在现行体育教学实际上, 我国多地公共体育课程还持续扮演着一门必修的课 程, 而技能的学习也只是建立在动作熟悉的基础之上, 体育教学应该是 “体教育人” 的基础, 体育的过程, 不仅仅停留在大学生体能的提高、技能的的增强, 还应伴随着 “德智” 的培育, 更多的是在这个过程中锻 炼大学生们的 “体力”、“心力”、“胆力”, 培养一种坚韧不拔的意志和顽强拼搏的人生态度。

\section{2 培养大学生 “软实力” 健身行为意识的构建}

大学生的健康体质好比是 “硬实力”, 体育健身行为意识好比是 “软实力”, 大学生在建立了良好体育 锻炼意识的前提下，才肯愿意积极参与各项体育运动，只有具备了产生对健身锻炼浓厚兴趣的同时，才能 逐渐养成锻炼的习惯, 从而促进体质的增强。而现行教育体制下, 无论是体育教育行为上还是文化教育体 制上, 由于过多注重课程任务教学和知识技能培养, 而忽略了学生自主学习和自主锻炼强化意识, 而就是 诸如此类的被动意识导致了大学生在健身意识上的薄弱, 没有彻底激发学生运动的细胞。大学校园体育文 化建设需要更多地大学生参与进来, 运动起来, 软实力的培养将有助于大学生提高对健身价值的取向和促 进体育锻炼行为, 更有助于校园体育文化的提升, 才能促使大学生把运动当成一种生活方式。

\section{3 坚守体育教学发展的科学性和系统性, 正确对待学生个性化追求}

高校公共体育课程教学的本质是通过有规律、有方法、有规则的身体运动知识来进行体育教学与参与, 以达到促进大学生心理健康、生理健康、人格健康的成长过程。坚持大学生以兴趣为导向、以快乐学习为 
取向固然重要, 但是两者都只是体育教学中的一个过程, 而非是体育教学的最终目的。高校在注重学生个 性发展的同时, 切勿忽略了体育教学的科学性与系统性以及体育育人的终极目的。体育作为高校教育的一 种方式，价值作用体现在于，以一种近乎挫折的实践教育，让运动者体验到超越自我的拼搏精神，锻炼出 一颗强大的内心, 学会去遵循社会规则、从内心正视和尊重对手, 能够摆正心态去正确面对失败与成功, 这也是任何教育方式都无法代替和比拟的。因此, 高校公共体育教育在应对学生个性化追求的同时, 也要 积极锻炼出学生勇于卓越的体育精神, 不要一味顾忌与放松对学生在意志力、体适能力和锻炼行为上的培 养与塑造, 因为体育是一项长期日积月累的健身行为, 坚守体育教学科学性和系统性的发展才能够真正培 养大学生健全独立的人格和勇于拼搏的精神。

\section{4 我国高校公共体育课程实践创新路径分析}

\section{1 优化大学生公共体育课程实践结构创新}

体育课程结构创新一直是我国改革的核心部位。随着教育事业的迅猛发展, 体育课程结构改革也应该 要与时俱进, 不断拓展创新。落实校园体育文化活动建设与组织及策划, 积极打造大学生课内外体育活动, 认真对待大学生个性化体育项目的发展, 鼓励大学生校内外体育竞赛的参与, 为大学生体育活动和竞赛活 动提供展示的机会与锻炼的平台。其次, 公共体育课程在注重学生技能掌握的同时更要倡导大学生健康锻 炼的价值观念, 针对大学生体育运动能力和技能掌握能力的不均衡, 应倡导道破常规体制, 打破原有的系 别、班级建制, 重新班组上课, 积极发挥教师的主导作用, 大学生的主体作用, 丰富公共体育课程内容、 结构、形式、手段、教学方法的灵活性和创新性, 进一步深化体育教学改革, 也实属创新突破之举。

\section{2 创新高校公共体育课程教育评价机制}

没有与时创新的的教育评价体制, 就不可能促进体育教学质量和教学效果的完善, 也不可能培养出一 批具备创新能力的新型复合性人才。然而, 对于存在的诸多问题, 还存在着形式化主义, 评价时 “轻结果、 轻过程”, 评价内容单一, 评价主体导向单一, 评价系数单调, 在机制的建立上没有完全结合大学生健康 发展的需求去完善体育教育机制, 真正的评价机制应该是全面多样化的, 而不是传统类型的对大学生进行 一种检查与测验, 是需要通过问题的提出而去落实与实施的, 落实体育评价机制, 就应该鼓励教师和大学 生围绕课程现行的诸多问题提出看法和建议, 从课程内容体系、课程结构设置、教师教学方法、课程管理 实施、教师师风道德、师资配备质量、体育健身场地、体育器材设备、课程教学目标、学生运动能力掌握、 教师教学教育目标等等着手去进行, 对落实 “以人为本, 健康第一” 的思想做出有力的推进和保障。

\section{3 促进公共体育课程教育实践创新, 培养大学生 “终身体育观”}

高校公共体育实践课程是建立在 “技艺为主、情感依托、自然和谐性、社会交际性”多重兼备的一门 以实践为基础的教育课程, 这是任何一门课程体系都无法代替的。公共体育课程面向全校大学生, 是培养 大学生掌握一门体育技能运用的基础, 通过对所选运动项目的精神寄托和情感宣泄达到体育锻炼身心的全 面发展, 是培养大学生自然对自我的超越, 也是培养大学生互帮互助、团结协作、勇于拼搏等精神的有效 途径。而公共体育课的教育实施理念也将深刻影响着实践创新的价值和效果, 加强实践拓展路线, 促进健 康体质优化, 增强大学生体育竞技行为, 提高学生体育自主学习能力, 培养学生积极体育健身强体观念, 才是体育育人的深层最终目标。 


\section{5 结论}

新时期的社会，健康视域下的中国，不论是在教育、文化、政治、经济上都面临着许多未知的机遇和 严峻的挑战，但是改革的思潮和创新的脚步从未停止，我国高等院校体育教育自新中国成立六十多年以来 颁布的每一步高校体育教学指导思想都始终把 “锻炼学生体质、增强学身体、教授体育知识与运动技能、 实施素质教育” 作为高校公共体育课程教学的四项基本任务, 不断对高校公共体育课程改革理论和实践创 新做出突破性举措, 不断开拓与发展以适应大学生们日新月异的健身需求和新时期下健身方式的新潮流, 体育是一项长期积累的过程, 需要坚强的意志和难能可贵的自我卓越品质, 无论改革的发展导向如何, 大 学生们都要积极培养自我强身健体的主动行为意识, 大学生健康体质促进需要改革理论和实践创新的支 撑, 但是同时也需要大学生们行为锻炼上的自我坚持, 在各高校努力优化公共体育课程的同时, 作为大学 生也应该积极把体育健身运动作为一种新型的生活方式，养成良好的锻炼习惯，促进自我身心全面健康发 展，促进校园体育文化可持续发展。

\section{参考文献}

[1] 白莉莉, 冯晓露. 立足体育本质, 反思当代学校体育误区一一熊晓正教授学术访谈录 [J]. 体育学刊, 2016, (02) : 1-4.

[2]张学军．我国普通高校公共体育课程改革研究评述 $[J]$ 。体育研究与教育, 2014, (06) : 32-36.

[3]戴福祥．新中国 60 年普通高校体育教学大纲的演变与经验 $[\mathrm{J}]$ 。成都体育学院学报, 2012, (12) :81-84.

[4]张茂泉. 高校公共体育课评价指标体系的构建研究 [J]. 南京体育学院学报 (自然科学版), 2010, (02) : 103-106.

[5]朱少青. 我国普通高校公共体育课教学改革现状与发展对策 $[\mathrm{A}]$ ． 《体育科研》2009 年第 3 期（总第 115 期） [C], 2009:3.

[6]王爱华．我国普通高校公共体育课程的创新性分析[J]。体育学刊, 2004, (05) :75-77.

\section{References}

[1] Bai Lili, Feng Xiaolu. Based On the Nature of Sports, Reflect on the Misunderstanding of Contemporary School Sports - Professor Xiong Xiaozheng Academic Interview [J]. Journal of Physical Education, 2016, (02): 1-4.

[2] Zhang Xuejun. Research Comment on China's Public Colleges and Universities in Public Physical Education Curriculum Reform [J]. Sports Research and Education, 2014, (06): 32-36.

[3] Dai Fuxiang. The Evolution and Experience of Physical Education Teaching Syllabus of New China's 60 Years Ordinary Universities[J] Journal of Chengdu Sport University, 2012, (12): 81-84.

[4] Zhang Maoquan. Investigation on Construction of Evaluation Index System of Public Physical Education in Colleges and Universities [J]. Journal of Nanjing Institute of Physical Education (Natural Science Edition), 2010, (02): 103-106.

[5] Zhu Shaoqing. Public Physical Education Teaching Reform Status and Development Countermeasures in China's Public Colleges and Universities [A]. The $3^{\text {rd }}$ edition (total 115 editions) Sports Research 2009 [C], 2009: 3.

[6] Wang Aihua. Innovation Analysis of China's Ordinary Colleges and Universities Public Sports Curriculum [J]. Journal of Physical Education, 2004, (05): 75-77. 